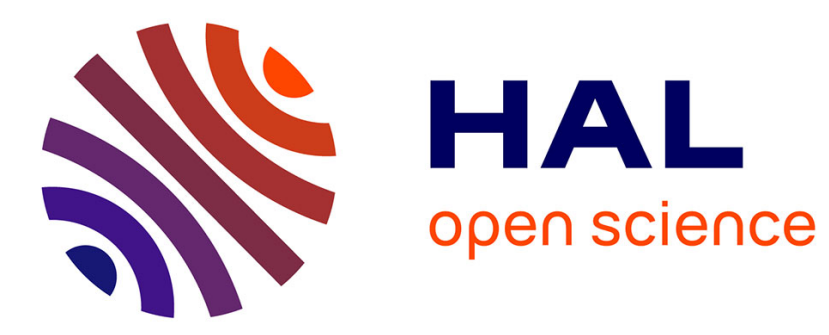

\title{
Onset of oscillatory flows in double-diffusive convection
} Kassem Ghorayeb, Hicham Khallouf, Abdelkader Mojtabi

\section{To cite this version:}

Kassem Ghorayeb, Hicham Khallouf, Abdelkader Mojtabi. Onset of oscillatory flows in doublediffusive convection. International Journal of Heat and Mass Transfer, 1999, 42 (4), pp.629-643. 10.1016/S0017-9310(98)00204-X . hal-01886729

\section{HAL Id: hal-01886729 \\ https://hal.science/hal-01886729}

Submitted on 3 Oct 2018

HAL is a multi-disciplinary open access archive for the deposit and dissemination of scientific research documents, whether they are published or not. The documents may come from teaching and research institutions in France or abroad, or from public or private research centers.
L'archive ouverte pluridisciplinaire HAL, est destinée au dépôt et à la diffusion de documents scientifiques de niveau recherche, publiés ou non, émanant des établissements d'enseignement et de recherche français ou étrangers, des laboratoires publics ou privés. 


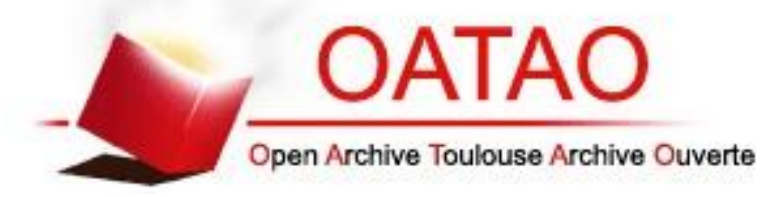

\section{Open Archive Toulouse Archive Ouverte}

OATAO is an open access repository that collects the work of Toulouse researchers and makes it freely available over the web where possible

This is an author's version published in: http://oatao.univ-toulouse.fr/20646

\section{Official URL:}

http://doi.org/10.1016/S0017-9310(98)00204-X

\section{To cite this version:}

Ghorayeb, K. and Khallouf, Hicham and Mojtabi, Abdelkader Onset of oscillatory flows in double-diffusive convection.

(1999) International Journal of Heat and Mass Transfer, 42 (4). 629-643. ISSN 0017-9310

Any correspondence concerning this service should be sent to the repository administrator: tech-oatao@listes-diff.inp-toulouse.fr 


\title{
Onset of oscillatory flows in double-diffusive convection
}

\author{
K. Ghorayeb ${ }^{\mathrm{a}, *}$, H. Khallouf ${ }^{\mathrm{b}}$, A. Mojtabi ${ }^{\mathrm{c}}$ \\ ${ }^{a}$ Reservoir Engineering Research Institute, 845 Page Mill Road, Palo Alto, CA 94304, U.S.A. \\ ${ }^{\mathrm{b}}$ M.I.P., U.F.R., M.I.G., 118 route de Narbonne, 31062 Toulouse Cedex, France \\ ${ }^{\mathrm{c}}$ U.M.R., 5502 IMFT-CNRS-UPS, U.F.R., M.I.G., 118 route de Narbonne, 31062 Toulouse Cedex, France
}

\begin{abstract}
A numerical study is presented of unsteady double-diffusive convection in a square cavity with equal but opposing horizontal temperature and concentration gradients. The boundary conditions along the vertical side-walls are imposed in such a way that the buoyancy ratio $N=G r_{\mathrm{S}} / G r_{\mathrm{T}}$ is equal to -1 , where $G r_{\mathrm{S}}$ and $G r_{\mathrm{T}}$ are the solutal and thermal Grashof numbers, respectively. In this situation, steady-state convective flow is stable up to a threshold value $G r_{\mathrm{c} 1}$ of the thermal Grashof number which depends on the Lewis number $L e$. Beyond $G r_{\mathrm{cl}}$, oscillatory convective flows occur. Here we study the transition, steady-state flow-oscillatory flow, as a function of the Lewis number. The Lewis number varies between 2 and 45. Depending on the values of the Lewis number, the oscillatory flow occurring for $G r_{\mathrm{T}}$ slightly larger than $G r_{\mathrm{cl}}$ is either centro-symmetric ( for $L e \geqslant 17$ ) or asymmetric single frequency flow (for $L e \leqslant 17$ ). For larger values of the thermal Grashof number, the two regimes occur for fixed values of $G r_{\mathrm{T}}$ and $L e$. Furthermore, computations show that $G r_{\mathrm{cl}}$ reaches a minimum equal to $4.75 \times 10^{4}$ for $L e \approx 7$. (C) 1998 Elsevier Science Ltd. All rights reserved.
\end{abstract}

\section{Nomenclature}

$C$ dimensionless concentration

$D$ solutal diffusivity

$G r_{\mathrm{cl}} \quad$ critical value of the thermal Grashof number corresponding to the onset of the oscillatory motion

$G r_{\mathrm{S}}$ solutal Grashof number

$G r_{\mathrm{T}}$ thermal Grashof number

$g$ gravitational acceleration

Le Lewis number

$N$ buoyancy ratio

$\mathrm{Nu}$ Nusselt number

$P$ dimensionless pressure

$\mathrm{P}$ dimensionless period of oscillation

$\mathrm{Pr}$ Prandtl number

$R a_{\mathrm{T}}$ thermal Rayleigh number

$R a_{\mathrm{c}} \quad$ critical value of the thermal Rayleigh number corresponding to the onset of convection

Sc Schmidt number

$S h$ Sherwood number

$t$ dimensionless time

$T$ dimensionless temperature
$\mathbf{U}$ dimensionless velocity vector

$u$ horizontal component of the velocity

$x, z$ dimensionless horizontal and vertical coordinates.

Greek symbols

$\beta_{\mathrm{C}}$ coefficient of solutal expansion

$\beta_{\mathrm{T}}$ coefficient of thermal expansion

$\chi$ thermal diffusivity

$\delta_{\mathrm{C}}$ solutal boundary layer

$\delta_{\mathrm{T}} \quad$ thermal boundary layer

$v$ kinematic viscosity

$\rho$ density

$\Psi$ stream-function.

\section{Introduction}

The behavior of a fluid subjected to the gradient of two properties with different diffusivities is called 'doublediffusive convection' [1]. Although 'double-diffusive convection' covers a wide range of phenomena such as oceanography, geology and crystal growth (Schmidt [2], Wilcox [3], Turner [4] and Huppert and Turner [5]), we shall restrict ourselves to the investigation of the structure of the steady and unsteady flows in a square cavity with

\footnotetext{
* Corresponding author
} 
horizontal heat and mass gradients due to constant temperatures and concentrations along the vertical sidewalls, respectively.

Double-diffusive convection in cavities with horizontal thermal and solutal gradients was the subject of several works in the two last decades since it is related closely to some physical processes such as the horizontal Bridgman crystal growth technique (Kamotani et al. [6]). During the growth of a crystal, the profound influence of the transport processes in the fluid phase on the structure and the quality of the solid phase requires a good understanding of the buoyancy convective flows in this problem.

Aside from the aspect ratio of the cavity, double diffusive convection involves four dimensionless parameters: the Prandtl number $\mathrm{Pr}$, the Schmidt number $\mathrm{Sc}$, and the solutal and thermal Grashof numbers $G r_{\mathrm{S}}$ and $G r_{\mathrm{T}}$, respectively (all of the parameters will be defined in section 2). However, the qualitative behavior of the doublediffusive induced flow depends mainly on the buoyancy ratio $N=G r_{\mathrm{S}} / G r_{\mathrm{T}}=\left(\beta_{\mathrm{C}} \Delta C\right) /\left(\beta_{\mathrm{T}} \Delta T\right)$ and the Lewis number $L e=S c / P r=\chi / D$ where $D, \chi, \beta_{\mathrm{C}}, \beta_{\mathrm{T}}, \Delta C$, and $\Delta T$ are the solutal and thermal diffusivities, the coefficients of solutal and thermal expansion, and the differences of concentrations and temperatures between the vertical side-walls, respectively. The question of the effect of the Lewis number and the buoyancy ratio on the flow structure when the temperature and the concentration are imposed along the vertical side-walls has been widely discussed by Bergeon et al. [7], Ghorayeb [21], and Bennacer [22].

Two situations are generally considered depending on the sign of the buoyancy ratio $N$. The solutal and thermal buoyancy contributions can cooperate $(N>0)$ or be opposite to each other $(N<0)$. In both cases, mono-cell and multi-cell flows have been experimentally observed and numerically computed, depending on the range of parameters considered. It should be mentioned that, a better agreement between experimental and numerical results has been observed when the solutal and thermal buoyancy forces cooperate than the case when they oppose to each other. This may perhaps be due to the unsteady convective motions which are generally observed in the 'opposing case' (Jiang et al. [8], Weaver and Viskanta [9], Ghorayeb [21] and Bergeon et al. [7]).

This paper is concerned with the numerical investigation of the onset of double-diffusive oscillatory flows in a square cavity when the ratio $N$ of solutal to thermal Grashof numbers is equal to -1 . This situation has been previously studied by Krishnan [26], Gobin and Bennacer [10], Xin et al. [12, 24], Ghorayeb [21], Ghorayeb and Mojtabi [13], Bergeon et al. [7], Nishimura et al. [14; $27-$ 28], and Zou and Zebib [15]. The choice $N=-1$ would be difficult to attain experimentally. However, we believe that the study of this particular situation provides a stepping stone to a better understanding of much more realistic situations in which $N$ differs from -1 . In such a situation, convective motions are induced by the difference between the thermal and the solutal diffusivities, $\chi$ and $D$, respectively.

When $N$ is equal to -1 , the purely diffusive solution is stable up to a critical value $R a_{c}$ of the thermal Rayleigh number $R a_{\mathrm{T}}\left(R a_{\mathrm{T}}=\operatorname{Pr} G r_{\mathrm{T}}\right)$. Linear analysis has been performed in order to evaluate this critical Rayleigh number $R a_{\mathrm{c}}$. Gobin and Bennacer [10] established that in an infinite vertical layer, the stability of the motionless solution only depends on $R a_{\mathrm{T}}(L e-1)$. They showed, following the analysis carried out by Thorpe et al. [11], that $R a_{c}=6122 /(L e-1)$. The analytical solution they obtained only satisfies the impermeability condition at the vertical side-walls. Ghorayeb and Mojtabi [13] and Xin et al. [12, 24] refined this analysis and established that $R a_{\mathrm{T}}=6509 /(L e-1)$, corresponding to the critical dimensionless wave number $k_{\mathrm{c}}=2.53$. More precisely, Ghorayeb and Mojtabi [13] considered vertical twodimensional bounded boxes of various finite extension. Their results show the evolution of the critical Rayleigh number with the aspect ratio. Using direct numerical simulations of convective solutions, they observed the existence of a wide variety of steady one-cell and multicell solutions for a fixed aspect ratio and Rayleigh number. Recently, Bergeon et al. [7] considered, using a continuation method, the mechanisms by which stable solutions lose stability or by which unstable solutions regain stability. They also studied the influence of the cavity inclination on the stability and bifurcating solutions. They found that the bifurcation at $R a_{\mathrm{c}}$ is either transcritical or pitchfork depending on the aspect ratio and the inclination of the cavity.

For the vertical square cavity, $R a_{\mathrm{c}}(L e-1)$ is equal to 17172 and the bifurcation at $R a_{\mathrm{c}}$ is transcritical [7, 12$13,24]$. Two branches of steady solutions emerge at $R a_{\mathrm{T}}=R a_{\mathrm{c}}$ (Fig. 1): the supercritical and the sub-critical ones. Both solutions are centro-symmetric. When we increase the thermal Grashof number beyond some value $\left(G r_{\mathrm{T}}=3035\right.$ for $L e=11$, for example), only one branch of solution remains stable (the sub-critical solution). The supercritical branch undergoes a pitchfork bifurcation and, consequently, loses stability. The other branch of solution (the sub-critical branch, designated by squares on Fig. 1) remains stable up to a critical value of the thermal Grashof number $G r_{\mathrm{cl}}$. At $G r_{\mathrm{cl}}$, it undergoes a Hopf bifurcation. Thus, the steady state flow loses stability and an oscillatory convective flow appears. The value of $G r_{\mathrm{cl}}$ depends on the Lewis number. Krishnan [26] studied this transition for $P r=1$ and $L e=3.161$ in a square cavity. He established that the transition convective steady flow-oscillatory flow occurs for $G r_{\mathrm{T}}=G r_{\mathrm{cl}}=$ $6.25 \times 10^{4}$. The oscillatory solution, which appears at $G r_{\mathrm{cl}}$, breaks the centro-symmetry and is a single frequency oscillatory flow.

Our work follows Krishnan's work [26]. We study 


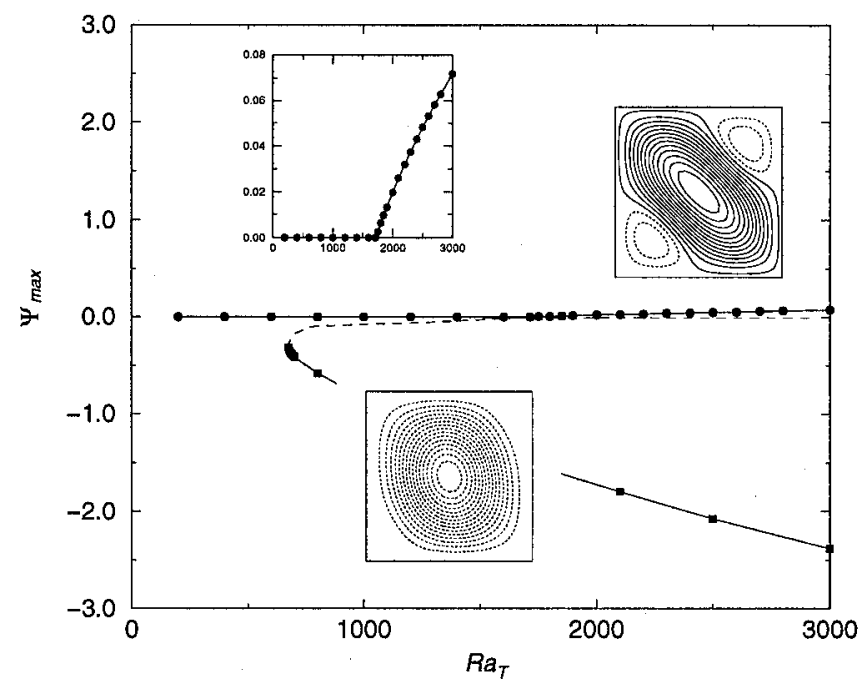

Fig. 1. Behavior of the extremum value of the dimensionless stream function as a function of the Rayleigh number for a square cavity, for both the supercritical regime (circles) and the sub-critical regime (squares). The zoom shows the supercritical regime in more detail. The dashed branch designates predictive mapping of the unstable solution branch [13].

the influence of the Lewis number on the steady flowoscillatory flow transition. We find that the nature of the oscillatory flow occurring for $G r_{\mathrm{T}}>G r_{\mathrm{c} 1}$ depends on the Lewis number. The oscillatory regime can be centrosymmetric or not, depending on the values of the Lewis number and the Grashof number. In this paper we consider the range (2-45) of the Lewis number. The Prandtl number is set equal to 1 in a square cavity. All the numerical simulations are performed for a square cavity. Very recently, Nishimura et al. [27] studied the effect of the buoyancy ratio on the transition steady state-oscillatory state in a cavity of aspect ratio $A=2$ for $P r=1, L e=2$ and $G r_{\mathrm{T}}=10^{5}$. This study shows that oscillatory flows occur not only for $N=-1$, but also for $N \in[-1.122$ $0.9]$. The authors also reported hysteresis of steady and oscillatory states in the range $N \in[-1.122-1.044]$. In two previous papers [27-28], the authors studied the same problem for the same range of parameters except for the aspect ratios; they considered cavities with aspect ratios $A=1$ [27] and $A=0.5$ [28].They reported that no oscillatory flows occur for those aspect ratios under the above flow conditions. This is in agreement with our result; for $A=1, L e=2$, our numerical simulations show that the transition steady state-oscillatory state occurs at $G r_{\mathrm{c} 1}=1.25 \times 10^{5}$. Zhou and Zebib [15] have studied the onset of double-diffusive oscillatory flows in a similar situation (crystal growth by physical vapor transport process where the horizontal velocity along the vertical sidewalls is proportional to the solutal flux). This study shows that the critical Grashof number depends on both the Lewis number and the aspect ratio of the cavity [15].

Our study is restricted to a range of the Grashof number where the oscillatory regime is found to be single frequency. However, as it was found by Krishnan [26], when we increase the Grashof number, the oscillatory regime undergoes two further bifurcations leading to states with incommensurate second and third frequencies. A typical power spectrum before broad band noise begins to grow contains three linearly distinct frequencies and several linear combinations of these frequencies. This behavior is the same as that reported by Gollub and Benson [16] for the Rayleigh-Bénard configuration. This important feature of the fluid behavior is not studied here. Our interest is only focused on understanding the onset of the oscillatory flow as a function of the Lewis number.

The paper is organised as follows: the next section outlines the mathematical formulation of the problem and the numerical method used to investigate it. The results are presented in the following section. We first study the structure of the steady state solution occurring before the transition steady state-oscillatory state. Then, the influence of the Lewis number on both the values of the Grashof number corresponding to this transition, and the structure of the oscillatory flow are studied.

\section{Mathematical formulation and numerical method}

\subsection{Mathematical formulation}

The system of equation is assumed to be unsteady state with no heat generation, viscous dissipation, chemical reactions or thermal radiation. The Oberbeck-Boussinesq approximation is assumed to be valid; thermo- 
physical properties are constant except in the buoyancy term where:

$\rho(T, C)=\rho_{0}\left(1-\beta_{\mathrm{T}}\left(T-T_{0}\right)-\beta_{\mathrm{C}}\left(C-C_{0}\right)\right)$.

Here: $\quad \rho_{0}=\rho\left(T_{0}, C_{0}\right), \quad \beta_{\mathrm{T}}=\left(-1 / \rho_{0}\right)(\partial \rho / \partial T)_{C} \quad$ and $\beta_{C}=\left(-1 / \rho_{0}\right)(\partial \rho / \partial C)_{\mathrm{T}}$ are the density at temperature $T_{0}$ and concentration $C_{0}$, the thermal expansion coefficient, and the solutal expansion coefficient, respectively. The conservation equations for momentum, mass, energy and species in dimensionless form are the following:

$\frac{\partial \mathbf{U}}{\partial t}+(\mathbf{U} \cdot \nabla) \mathbf{U}=-\nabla P+\nabla^{2} \mathbf{U}-\left(G r_{\mathrm{T}} T+G r_{S} C\right) k$,

$\nabla \cdot \mathbf{U}=0$

$\frac{\partial T}{\partial t}+\mathbf{U} \cdot \nabla T=\frac{1}{P r} \nabla^{2} T$,

$\frac{\partial C}{\partial t}+\mathbf{U} \cdot \nabla C=\frac{1}{S c} \nabla^{2} C$,

where

$G r_{\mathrm{T}}=\frac{g \beta_{\mathrm{T}} \Delta T L^{3}}{v^{2}}$ is the thermal Grashof number,

$G r_{S}=\frac{g \beta_{\mathrm{C}} \delta C L^{3}}{v^{2}}$ is the solutal Grashof number,

$\operatorname{Pr}=\frac{v}{\chi}$ is the Prandtl number and,

$S c=\frac{v}{D}$ is the Schmidt number.

$D, \chi, v$ and $g$, are the solutal diffusivity, the thermal diffusivity, the kinematic viscosity, and the gravity acceleration, respectively. The corresponding boundary conditions (Fig. 2) are:

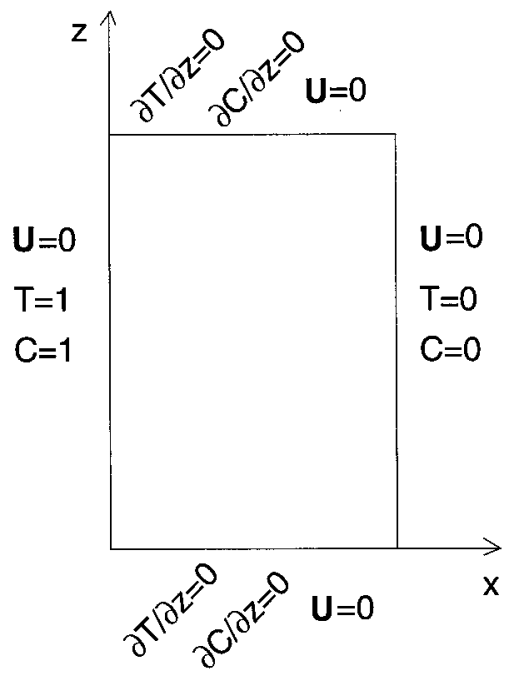

Fig. 2. Definition's scheme.
$\mathbf{U}=0 \quad(x=0, x=1, \forall z \quad$ and $\quad z=0, z=1, \forall x)$,

$T=C=1 \quad(x=0, \forall z)$,

$T=C=0 \quad(x=1, \forall z)$,

$\frac{\partial T}{\partial z}=\frac{\partial C}{\partial z}=0 \quad(z=0, z=1, \forall x)$.

In the above equations, lengths are nondimensionalized by $L$, velocity by $v / L$, time by $L^{2} / v$, temperature by $\Delta T=T_{2}-T_{1}$ and concentration by $\Delta C=C_{2}-C_{1} . T_{1}, C_{1}$, $T_{2}$, and $C_{2}$ are the temperature and the concentration at $x=0$ and $x=L$, respectively. We assume that $\beta_{\mathrm{T}}>0$ and $\beta_{\mathrm{C}}<0(\rho$ increases with $C$ and decreases with $T)$ and that $T_{1}>T_{2}$ and $C_{1}>C_{2}$. These assumptions lead to: $G r_{\mathrm{T}}>0$ and $G r_{\mathrm{S}}<0$. The buoyancy ratio $N=G r_{\mathrm{S}} /$ $G r_{\mathrm{T}}=-1$ and the aspect ratio $A$ is set equal to 1 .

Equations (1)-(4) together with the boundary conditions (5)-(8) are symmetric with respect to the following centro-symmetry operator:

$\left(\begin{array}{c}\mathbf{U}(x, z) \\ T(x, z) \\ C(x, z)\end{array}\right) \rightarrow\left(\begin{array}{l}-\mathbf{U}(1-x, 1-z) \\ -T(1-x, 1-z) \\ -C(1-x, 1-z)\end{array}\right)$.

As reported by Ghorayeb and Mojtabi [13], and Bergeon et al. [7], all of the stable solutions observed numerically in the square cavity are symmetric with respect to the above operator.

\subsection{Numerical scheme}

The numerical method used here is based on the projection diffusion algorithm developed by Batoul et al. [17] for solving two-dimensional unsteady incompressible Navier-Stokes equations. The temporal integration consists of a semi-implicit second-order finite differences approximation. The linear (viscous) terms are treated implicitly by the second-order Euler backward scheme, while a second-order explicit Adams-Bashforth scheme is used to approximate the non-linear (advective) parts. A high-accuracy spectral method, namely the Chebyshev collocation method, with the Gauss-Lobatto zeros as collocation points, is used for the spatial discretization [23]. The code has been used by Labrosse et al. [20] to study the transition to unsteadiness of natural convection flow in a differentially heated cavity. The results obtained by those authors agree extremely well with previous studies. Furthermore, the results we present in this work are in good agreement with those obtained by Krishnan [26] using a finite element numerical code.

\section{Results and discussion}

The study aims to compute the critical Grashof number $G r_{\mathrm{cl}}$ beyond which the steady state convective flow loses stability in a square cavity. The nature of the oscillatory 
flows occurring for $G r_{\mathrm{T}}>G r_{\mathrm{c} 1}$ is also studied. The flow structure and the heat and mass transfers depend on the Lewis number. Our study is performed for values of the Lewis number between 2 and 45 . However, our numerical simulations show that for $L e>17, G r_{\mathrm{c} 1}$ and the oscillation frequency vary linearly with $L e$.

The study is performed using $31 \times 31$ and $41 \times 41$ meshes for $L e \leqslant 21$ and $L e>21$, respectively. Table 1 shows the mesh influence on the Nusselt number $\mathrm{Nu}$, the Sherwood number $S h$, and the stream function in the middle of the cavity for $L e=21$ and $G r_{\mathrm{T}}=6.5 \times 10^{4}$ (slightly lower than $G r_{\mathrm{c} 1}$ ). This table shows that the results obtained for the $31 \times 31$ mesh differs by less than $0.5 \%$ from those obtained for the $41 \times 41$ mesh. With regard to the time step, it varies between $10^{-4}-5 \times 10^{-5}$ depending on the values of $L e$ and $G r_{\mathrm{T}}$. Our numerical simulations show that, in the whole range of parameters we studied, further refinement of grid size and time step results in less than $0.5 \%$ of uncertainty both in terms of heat and mass transfers, and the oscillation frequency.

In order to compute the critical Grashof number which corresponds to the steady flow-oscillatory flow transition, we progressively increase $G r_{\mathrm{T}}$ with a given step $\delta G r_{\mathrm{T}}$ until the steady state loses stability. We compute the solution for $G r_{\mathrm{T}}+\delta G r_{\mathrm{T}}$ starting with initial conditions corresponding to $G r_{\mathrm{T}}$. Once the oscillatory flow is obtained, we progressively decrease $G r_{\mathrm{T}}$ with small step $\delta G r_{\mathrm{T}}$ starting this time with the oscillatory regime as initial condition for the numerical simulations. It should be noted that, the lower $\left|G r_{\mathrm{T}}-G r_{\mathrm{cl}}\right|$, the higher the transition time is. The closer one gets to the critical Grashof number, the slower the oscillations decay or grow. For instance, the critical Grashof number is obtained with less than $2 \%$ accuracy.

\subsection{Steady state flow structure $\left(G r_{\mathrm{T}}<G r_{\mathrm{cl}}\right)$}

The experimental and numerical studies using large Lewis number binary fluids show a very thin solutal boundary layer. Suppose that the vertical side-walls of the cavity are maintained at temperatures (concentrations) $T_{1}$ and $T_{2}\left(C_{1}\right.$ and $\left.C_{2}\right)$ respectively. The thermal (solutal) boundary layer $\delta_{\mathrm{T}}\left(\delta_{\mathrm{C}}\right)$ near the wall $x=0$,

Table 1

Resolution effect: $L e=21, G r_{\mathrm{T}}=6.5 \times 10^{4}$ (slightly lower than $\left.G r_{\mathrm{cl} 1}\right)$

\begin{tabular}{llcl}
\hline$M$ & $N u$ & $S h$ & $\Psi$ (center) \\
\hline 21 & 3.59370 & 9.994 & -9.3266 \\
31 & 3.64771 & 10.80 & -9.4744 \\
41 & 3.64416 & 10.78 & -9.4643 \\
51 & 3.64443 & 10.77 & -9.4647 \\
\hline
\end{tabular}

for instance, is defined as the distance across which the temperature (concentration) varies from $T_{1}\left(C_{1}\right)$ to $\left(T_{1}+T_{2}\right) / 2\left(\left(C_{1}+C_{2}\right) / 2\right) . \delta_{\mathrm{T}}\left(\delta_{\mathrm{C}}\right)$ depends evidently on $z$. Our numerical simulations show that the thermal and solutal boundary layer thicknesses are minimum for $z=0.2$ (for the square cavity). We designate, subsequently, the boundary layer thickness that corresponding to $z \approx 0.2$. When the Lewis number is larger than 1 , the ratio $\delta_{\mathrm{T}} / \delta_{\mathrm{C}}$ is thus larger than 1 . This ratio becomes more important when Le increases. The concentration outside the vertical solutal boundary layer is almost constant. The small solutal gradient outside the thin solutal boundary layer leads to thermally driven buoyancy forces in the core of the cavity. Wang et al. [25] suggested that the ratio of the thermal to the solutal boundary layer thicknesses is of the order of:

$\frac{\delta_{\mathrm{T}}}{\delta_{\mathrm{c}}}=(|N| L e)^{1 / 4}$.

This result is effectively observed in several numerical and experimental studies (Kamotani et al. [6]; Lee and Hyun [18]; Hyun and Lee [19]). It confirms the result obtained by the thermo-solutal boundary layer analysis for a fluid in which the thermal buoyancy force dominates the solutal one [22] (i.e., the density variations in the fluid are mainly caused by thermal buoyancy forces). However, the thermo-solutal boundary layer analysis shows that, in the opposite case, where the solutal buoyancy force dominates the thermal buoyancy force, one obtains [22]

$\frac{\delta_{\mathrm{T}}}{\delta_{\mathrm{C}}}=L e^{1 / 3}$.

These results are obtained for large Lewis number.

For $N=-1$, the case we study, we investigated the influence of the Lewis number on the thermal and solutal boundary layers. It should firstly be mentioned that the mesh we use (Gauss-Labatto collocation points) is particularly suitable for the study where thin boundary layers occur. Figure 3 shows both the iso-concentration lines and the mesh for $\left(L e=21, G r_{\mathrm{T}}=69000\right)\left(G r_{\mathrm{c} 1}=70000\right)$ where four collocation points are in the solutal boundary layer. Figures 4 and 5 show the solutal and thermal boundary layers as a function of the Lewis number. The corresponding Grashof numbers are slightly lower than the critical Grashof numbers. Figure 5 shows that, the thermal boundary layer is not significantly influenced when the Lewis number varies (the Prandtl number is set equal to -1$)$. We find, in the range of parameters we study, that:

$\frac{\delta_{\mathrm{T}}}{\delta_{\mathrm{C}}}=L e^{0.3657}$.

Figure 6 shows $\delta_{\mathrm{T}} / \delta_{\mathrm{C}}$ numerically obtained and the analytical approximation obtained by eqns (10) and (11). On a $\log -\log$ graph, $\delta_{\mathrm{T}} / \delta_{\mathrm{C}}$ increases linearly with $L e$. The 


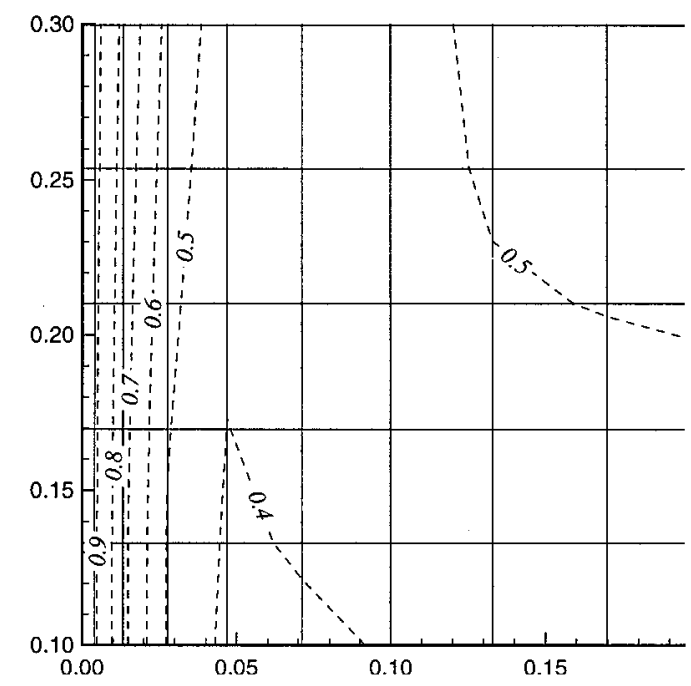

Fig. 3. Solutal boundary layer for $L e=21, G r_{\mathrm{T}}=69000,31 \times 31$ mesh. Four collocation points are in the boundary layer.

slope of this linear curve is 0.3657 . This result differs by less than $10 \%$ from the results obtained by equation (11).

\subsection{Oscillatory regimes}

Figure 7 summarizes the principal results concerning $G r_{\mathrm{c} 1}$ and the structure flow for $G r_{\mathrm{T}}>G r_{\mathrm{cl} 1} . G r_{\mathrm{c} 1}$ depends on the value of the Lewis number. The curve $\mathrm{X}_{2} O \mathrm{O}_{4}$ designates the critical Grashof number as a function of the Lewis number. For the values of $\left(L e, G r_{\mathrm{T}}\right)$ below this curve we obtain a steady state convective flow. $G r_{\mathrm{cl}}$ reaches a minimal value equal to $4.25 \times 10^{4}$ for $L e \approx 7$. The point $O\left(L e=17, G r_{\mathrm{T}}=6.4 \times 10^{4}\right)$ divides this curve into two parts. For $L e>17, G r_{\mathrm{cl}}$ varies almost linearly as function of $L e$. The $(\bullet)$ on the curve $O X_{2}$ designates the value reported by Krishnan [26] for the transition steady flow-oscillatory flow. This value agrees very well with our results. It should be noted that the steady state convective flow $\left(G r_{\mathrm{T}}<G r_{\mathrm{cl}}\right)$ is shown to be centro-symmetric for all values of $L e$ considered in this study. However, the oscillatory flow is either centro-symmetric or not depending on the values of $\left(L e, G r_{\mathrm{T}}\right)$. With regard to the nature of the oscillatory flow obtained for the values of $\left(\mathrm{Le}, \mathrm{Gr}_{\mathrm{T}}\right)$ above the curve $\mathrm{X}_{2} \mathrm{OX}_{4}$, three zones of the oscillatory flow structure can be distinguished (Fig. 7).

\subsection{1. $\mathrm{S}_{b}$ : centro-symmetry breaking regime}

This region is bounded by the curves $O X_{1}$ and $O X_{2}$. The flow in this region breaks the centro-symmetry. The flow structure on a half of a period is symmetric to that corresponding to the other half of the period with respect to the middle of the cavity. Let $\mathrm{P}$ be the oscillation period for some couple $\left(L e, G r_{\mathrm{T}}\right)$ in this zone. the flow at the time $t$ of this period is symmetric, with respect to the middle of the cavity, to that corresponding to the time $t+\mathrm{P} / 2$. We designate by 'temporal symmetry' the last flow behavior. It should be mentioned that Krishnan [26] has only observed the centro-symmetry breaking solution. Figure 8 shows the flow structure during a period for $L e=11, G r_{\mathrm{T}}=4.75 \times 10^{4}\left(G r_{\mathrm{cl} 1}=4.67 \times 10^{4}\right)$. The temporal symmetry is clearly shown on this figure. The flow in this zone is a single-frequency one.

\subsection{2. $\mathrm{S}_{c}$ : centro-symmetric regime}

The oscillatory flow obtained for the values of $\left(L e, G r_{\mathrm{T}}\right)$ bounded by the curves $O X_{3}$ and $O X_{4}$ is centrosymmetric. However, temporal symmetry does not occur. Figure 9 shows the flow structure during a period for $L e=21, G r_{\mathrm{T}}=7.0 \times 10^{4}\left(G r_{\mathrm{cl}}=6.9 \times 10^{4}\right)$.

\subsection{3. $\mathrm{S}_{b c}$ : multiple oscillatory flows}

For the values of $\left(L e, G r_{\mathrm{T}}\right)$ which are above the curve $X_{1} O X_{3}\left(S_{\mathrm{bc}}\right.$ zone), our numerical simulations show that both centro-symmetry oscillatory flow and symmetry breaking oscillatory flow occur for fixed values of $\left(L e, G r_{\mathrm{T}}\right)$. There are multiple oscillatory flows. This depends on the initial conditions of the numerical simulation. The symmetry properties of a solution in this region are the same of that corresponding to the initial conditions of this numerical simulation. Figures 10 and 11 show the flow structure during a period for both the centro-symmetric oscillatory solution and the symmetry breaking oscillatory solution obtained for $(L e=11$, $\left.G r_{\mathrm{T}}=7.0 \times 10^{4}\right)$ and $\left(L e=21, G r_{\mathrm{T}}=9.0 \times 10^{4}\right)$, respectively. Figure 12(a) shows how the oscillatory solution loses the centro-symmetry property when the numerical simulation is performed for $\left(L e, G r_{\mathrm{T}}\right)$ in the $\left(S_{\mathrm{b}}\right)$ zone starting with initial conditions corresponding to a centrosymmetric solution in the $S_{\mathrm{bc}}$ zone. The opposite case is shown in Fig. 12(b) which shows how the oscillatory solution becomes centro-symmetric when the numercial simulation is performed for $\left(L e, G r_{\mathrm{T}}\right)$ in the $\left(S_{\mathrm{c}}\right)$ zone starting with initial conditions corresponding to a centrosymmetry breaking solution in the $S_{\text {bc }}$ zone. Figure 13(af) shows the behavior of the Nusselt number as function of time, the power of the specter as function of the frequency, and the Sherwood number as function of the Nusselt number for $L e=11, G r_{\mathrm{T}}=7.0 \times 10^{4}$ (left) and $L e=21, G r_{\mathrm{T}}=9.0 \times 10^{4}$ (right). We can see that the oscillation frequency for the centro-symmetric solution is larger than the oscillation frequency for the centrosymmetry breaking solution. We can also see that the amplitude of the oscillation is larger for the centro-symmetry breaking solution than that of the centro-symmetric solution.

\subsubsection{Remarks and discussion}

In Figs 8 and 9, small solutal blobs are pinched off (contour $C=0.5$ in Fig. 8 and contours $C=0.4$ and 


$$
\text { Le }=2
$$

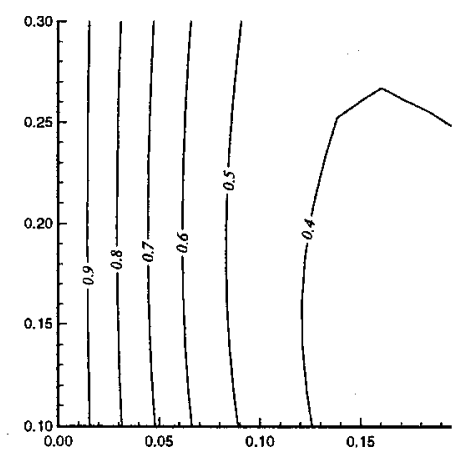

$\mathrm{Le}=15$

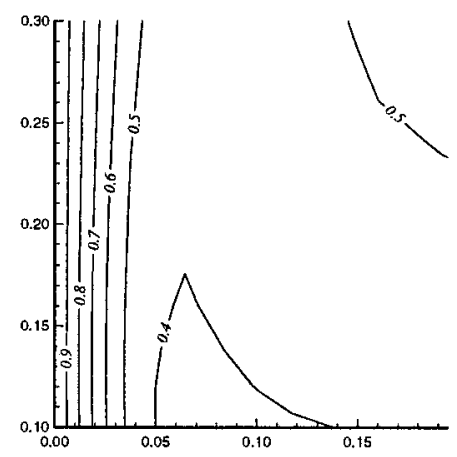

$$
\mathrm{Le}=25
$$

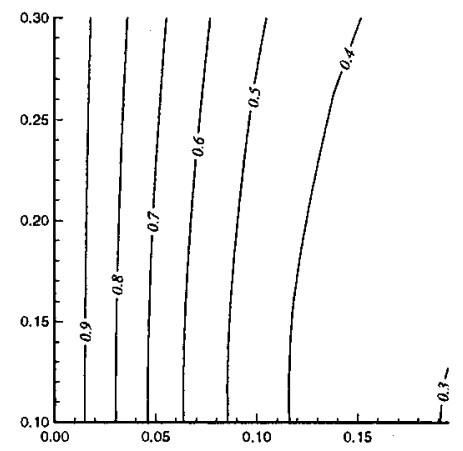

$\mathrm{Le}=7$

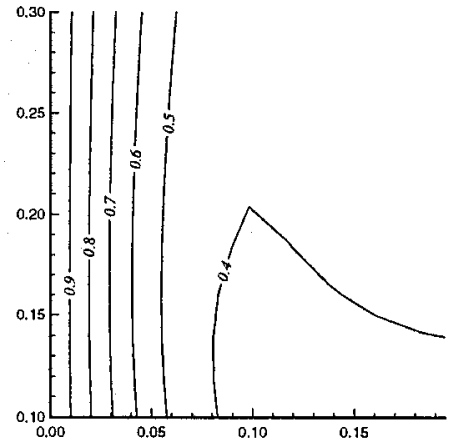

$\mathrm{Le}=17$

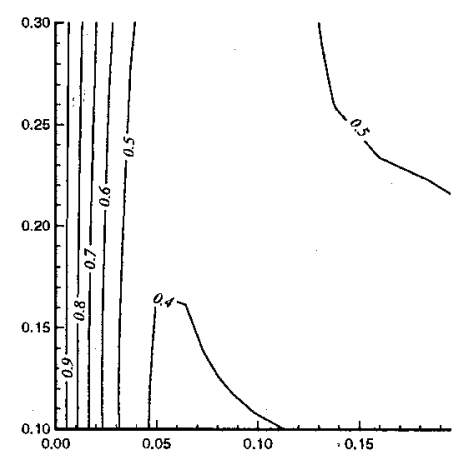

$$
\mathrm{Le}=35
$$

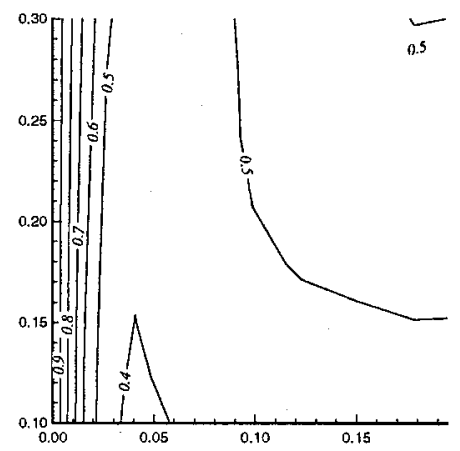

Fig. 4. Solutal boundary layer for $L e=2,7,15,17,25$, and 35 corresponding to $G r_{\mathrm{T}}=1.2 \times 10^{5}, 4.1 \times 10^{4}, 5.9 \times 10^{4}, 6.4 \times 10^{4}, 7.1 \times 10^{4}$, and $8.25 \times 10^{4}$, respectively (values slightly lower than $G r_{\mathrm{cl}}$ ). The meshes used are $31 \times 31$ and $41 \times 41$ for $L e \leqslant 21$ and $L e>21$, respectively. 

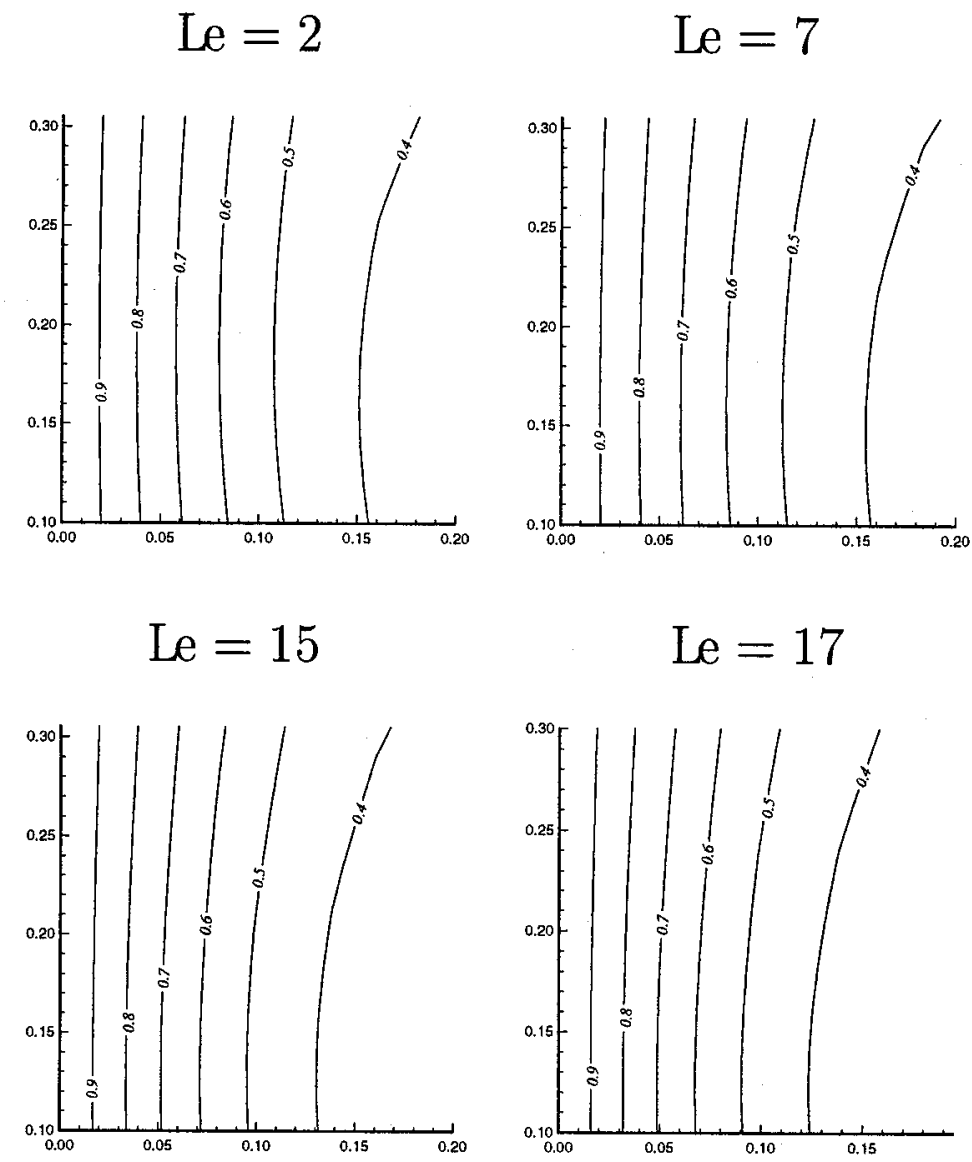

$$
\text { Le }=25
$$

$$
\text { Le }=35
$$
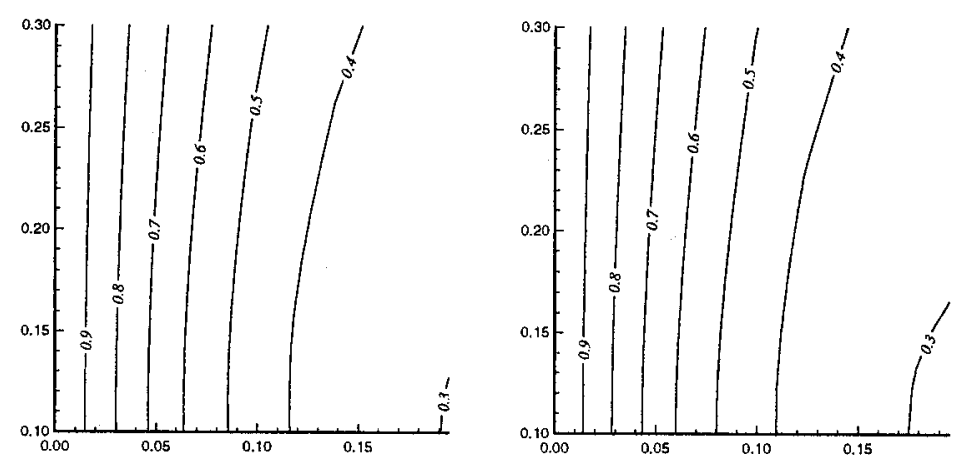

Fig. 5. Thermal boundary layer for $L e=2,7,16,17,25$, and 35 corresponding to $G r_{\mathrm{T}}=1.2 \times 10^{5}, 4.1 \times 10^{4}, 5.9 \times 10^{4}, 6.4 \times 10^{4}, 7.1 \times 10^{4}$, and $8.25 \times 10^{4}$, respectively (values slightly lower than $G r_{\mathrm{cl}}$ ). The meshes used are $31 \times 31$ and $41 \times 41$ for $L e \leqslant 21$ and $L e>21$, respectively. 

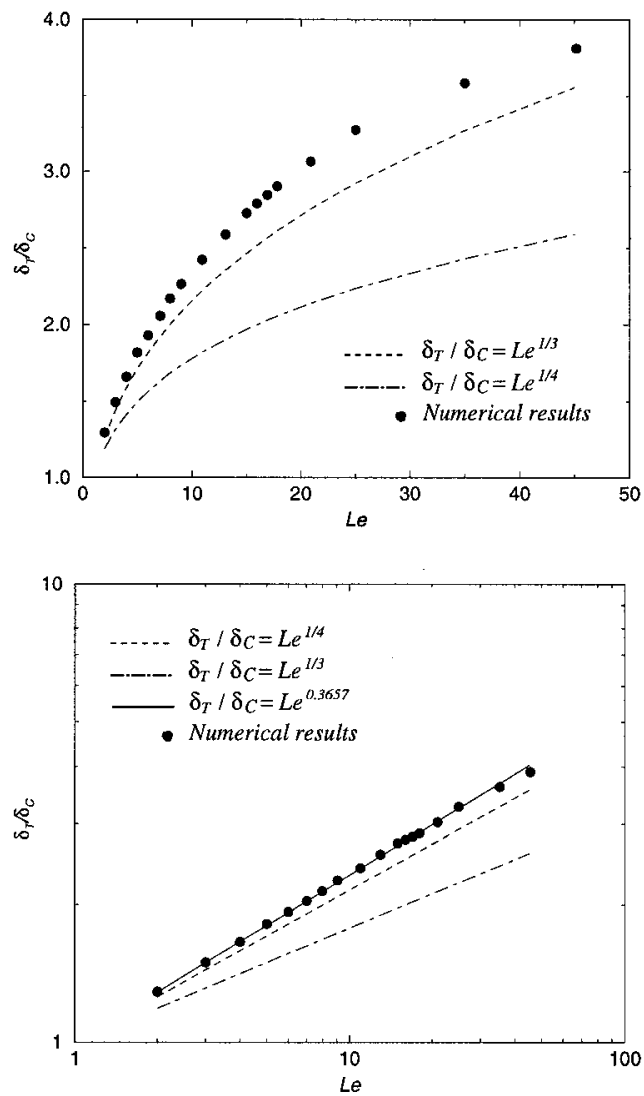

Fig. 6. $\delta_{\mathrm{T}} / \delta_{\mathrm{C}}$ is presented as function $L e$ (top). • dashed, and dot-dashed lines designate our numerical results and the curves $\delta_{\mathrm{T}} / \delta_{\mathrm{C}}=L e^{1 / 3}$ and $\delta_{\mathrm{T}} / \delta_{\mathrm{C}}=L e^{1 / 4}$ obtained by the thermo-solutal boundary layer analysis, respectively. The figure in bottom presents the same curves in a log-log graph. The curve plotted in the solid line designates $\delta_{\mathrm{T}} / \delta_{\mathrm{C}}=L e^{0.3657}$

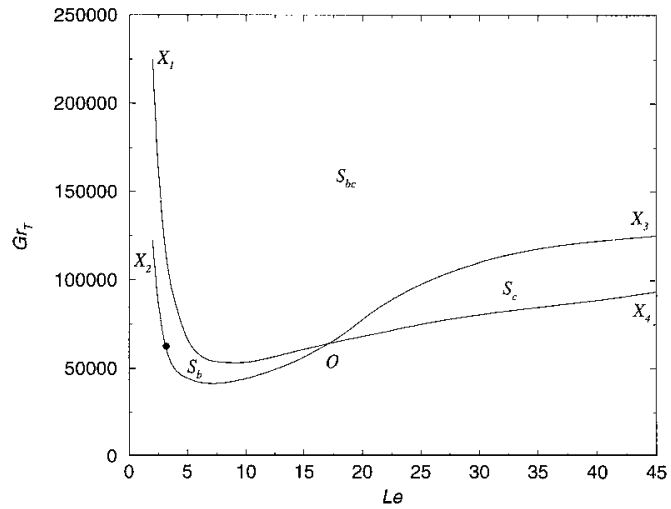

Fig. 7. Various zones of oscillatory flows as function of $\left(G r_{\mathrm{T}}, L e\right)$. Below $\mathrm{X}_{2} \mathrm{OX}_{4}$ : steady state centro-symmetric regime. $\mathrm{X}_{2} \mathrm{OX}_{4}$ is the threshold of this regime. $S_{\mathrm{b}}$ : symmetry breaking oscillatory regime. $S_{c}$ : centro-symmetric oscillatory regime. $S_{\mathrm{bc}}$ (above $X_{1} O X_{3}$ ): coexistence of both oscillatory regimes for fixed $\left(G r_{\mathrm{T}}, L e\right)$. $\bullet$ indicates the steady state-oscillatory state threshold obtained by Krishnan [26] for $L e=3.161$.

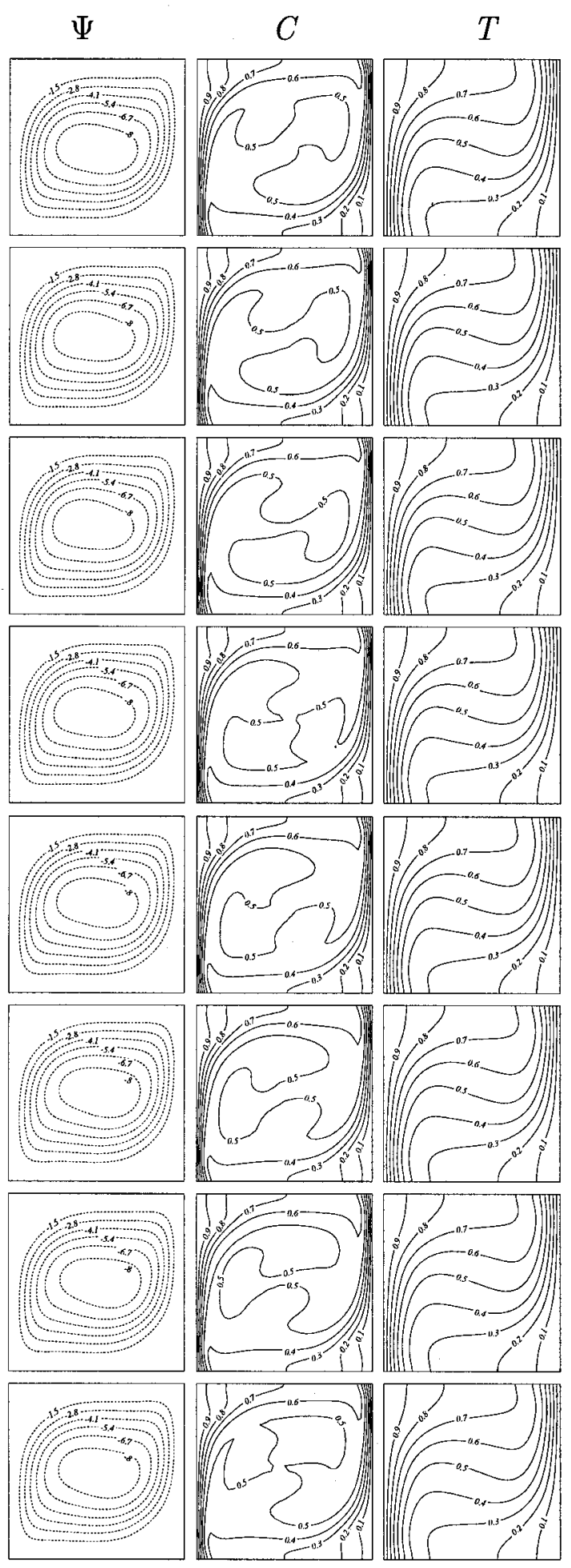

Fig. 8. Flow structure during eight moments of a period. Contours of the stream-function, concentration and temperature fields are shown. $L e=11, G r_{\mathrm{T}}=4.75 \times 10^{4}$, Resolution is $31 \times 31$, time step is $10^{-4}$. 


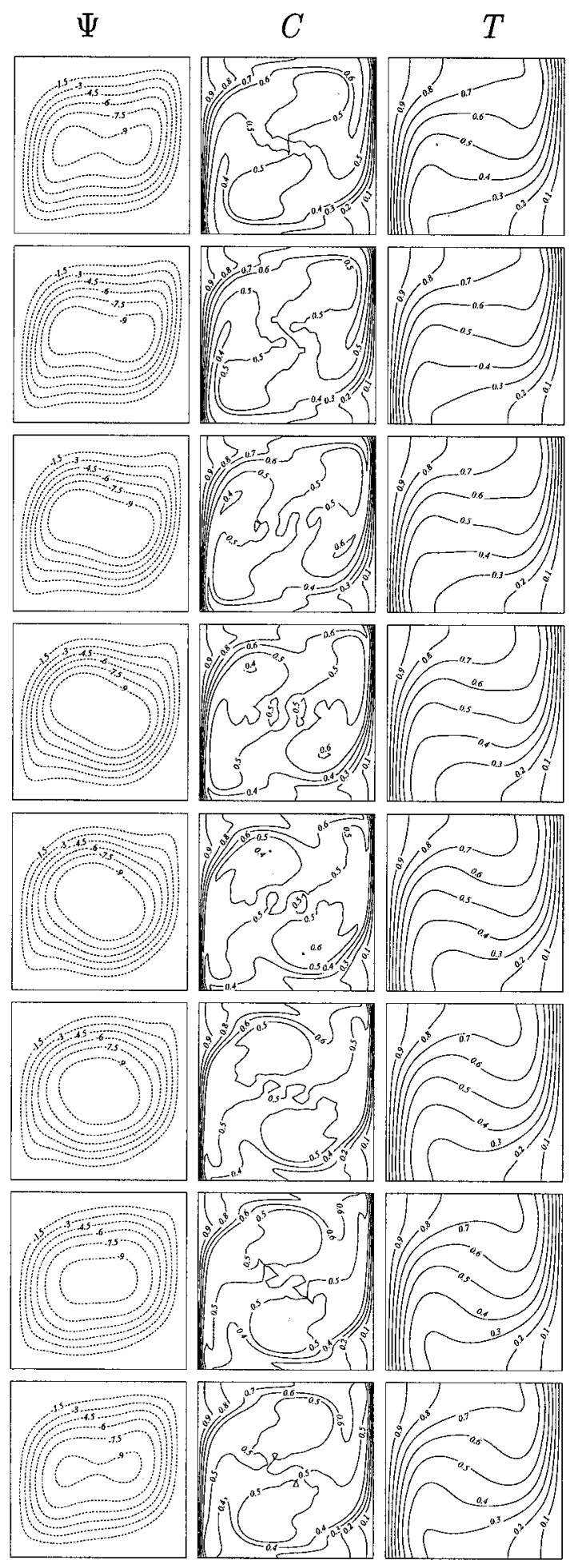

Fig. 9. Flow structure during eight moments of a period. Contours of the stream-function, concentration, and temperature fields are shown. $L e=21, G r_{\mathrm{T}}=7.0 \times 10^{4}$, Resolution is $31 \times 31$, time step is $10^{-4}$
$C=0.6$ in Fig. 9). These blobs appear only over a small part of the time cycle. Over the remainder part of the oscillation period, they are dissipated away by the effect of solutal diffusion. Those figures designate the flow for Grashof numbers slightly greater than the critical Grashof number. The size of these blobs is shown to be closely related to the Lewis number and the Grashof number. This size increases with $L e$. With an increasing Grashof number, the solutal blobs become bigger and present throughout the time cycle (Figs 10 and 11). The number of blobs also increases with the Grashof number. The presence of the solutal blobs has been reported by Krishnan [26], to be the cause of the oscillatory flow in the fluid.

\section{Conclusion}

Numerical simulations of unsteady double-diffusive convection in a square cavity, with equal and opposing buoyancy forces due to horizontal thermal and concentration gradients were carried out. The presented results exhibit the influence of the Lewis number on the transition steady state convective flow-oscillatory flow, and the oscillatory flow structure occurring beyond this transition. The range (2-45) of the Lewis number has been studied. The convective steady state flow is centrosymmetric regardless of the value of Le. However, the oscillatory flow which occurs after the transition steady state-oscillatory state is either centro-symmetric or asymmetric depending on the value of the Lewis number. Furthermore, it is found that, depending on the values of $\left(L e, G r_{\mathrm{T}}\left(>G r_{\mathrm{c} 1}\right)\right)$, results show three situations of the oscillatory flow. The first is where only the asymmetric oscillatory flow occurs. The second is where only the centro-symmetric oscillatory flow occurs. The third is where both oscillatory flows occur for fixed values of $\left(L e, G r_{\mathrm{T}}\right)$. In the range of $\left(L e, G r_{\mathrm{T}}\right)$ studied, the oscillatory flow is shown to be single frequency. Computations have been repeated for finer mesh and time step. This should confirm the quantitative and qualitative validity of our results.

\section{Acknowledgements}

This work has been carried out with the support of the Centre Nationale d'Etudes Spatiales (CNES), France. Computations were carried out on the DEC ALPHA 2100 4/275 of the Laboratoire de Mathématiques pour l'Industrie et la Physique (MIP). The authors thank A. Bergeon and R. Sani for fruitful discussions. 

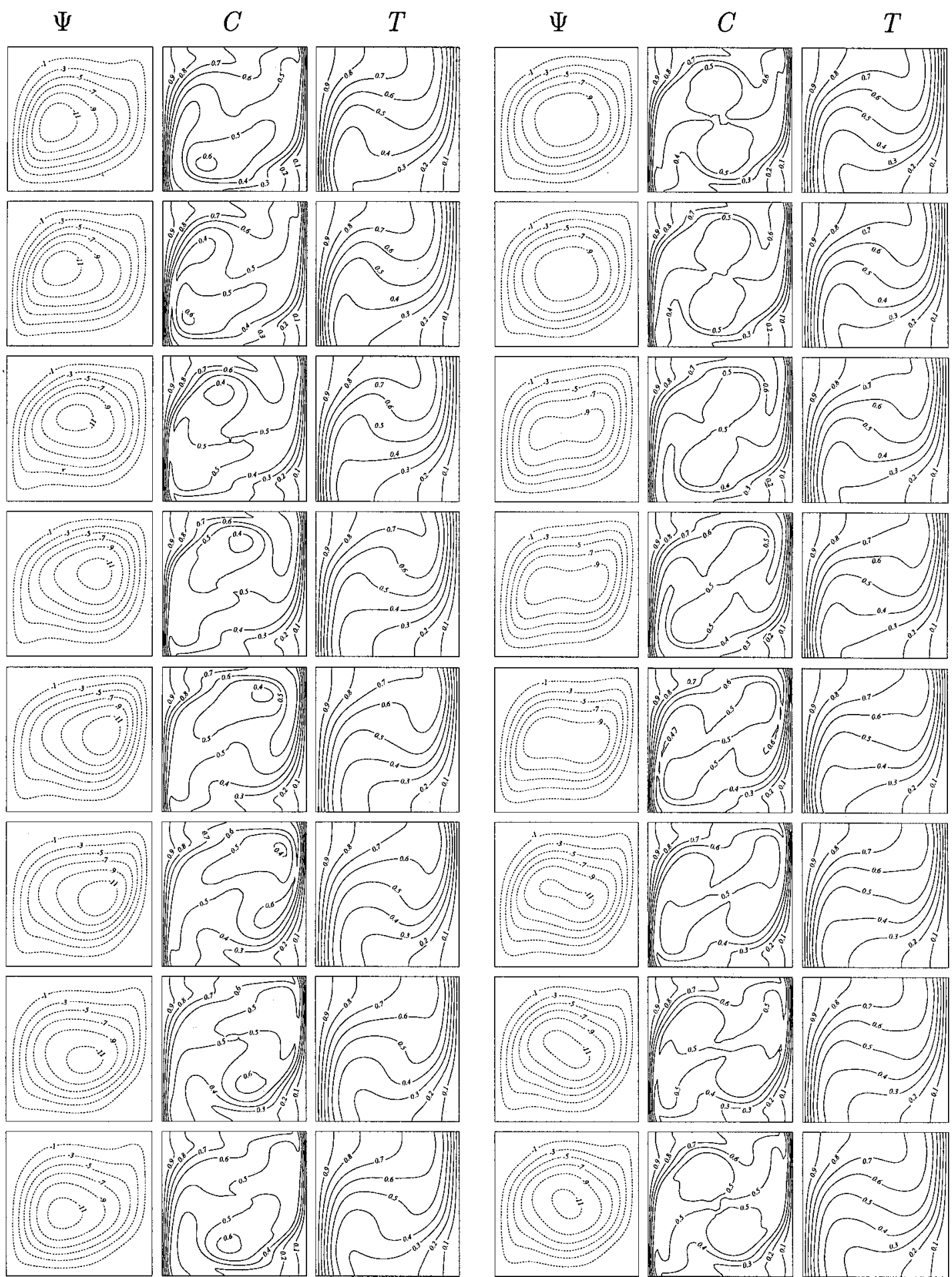

Fig. 10. Flow structure during eight moments of a period. Contours of the stream-function, concentration, and temperature fields are shown, the symmetry-breaking solution (left) and the centro-symmetric solution (right). $L e=11, G r_{\mathrm{T}}=7.0 \times 10^{4}$, Resolution is $31 \times 31$, time step is $10^{-4}$ 


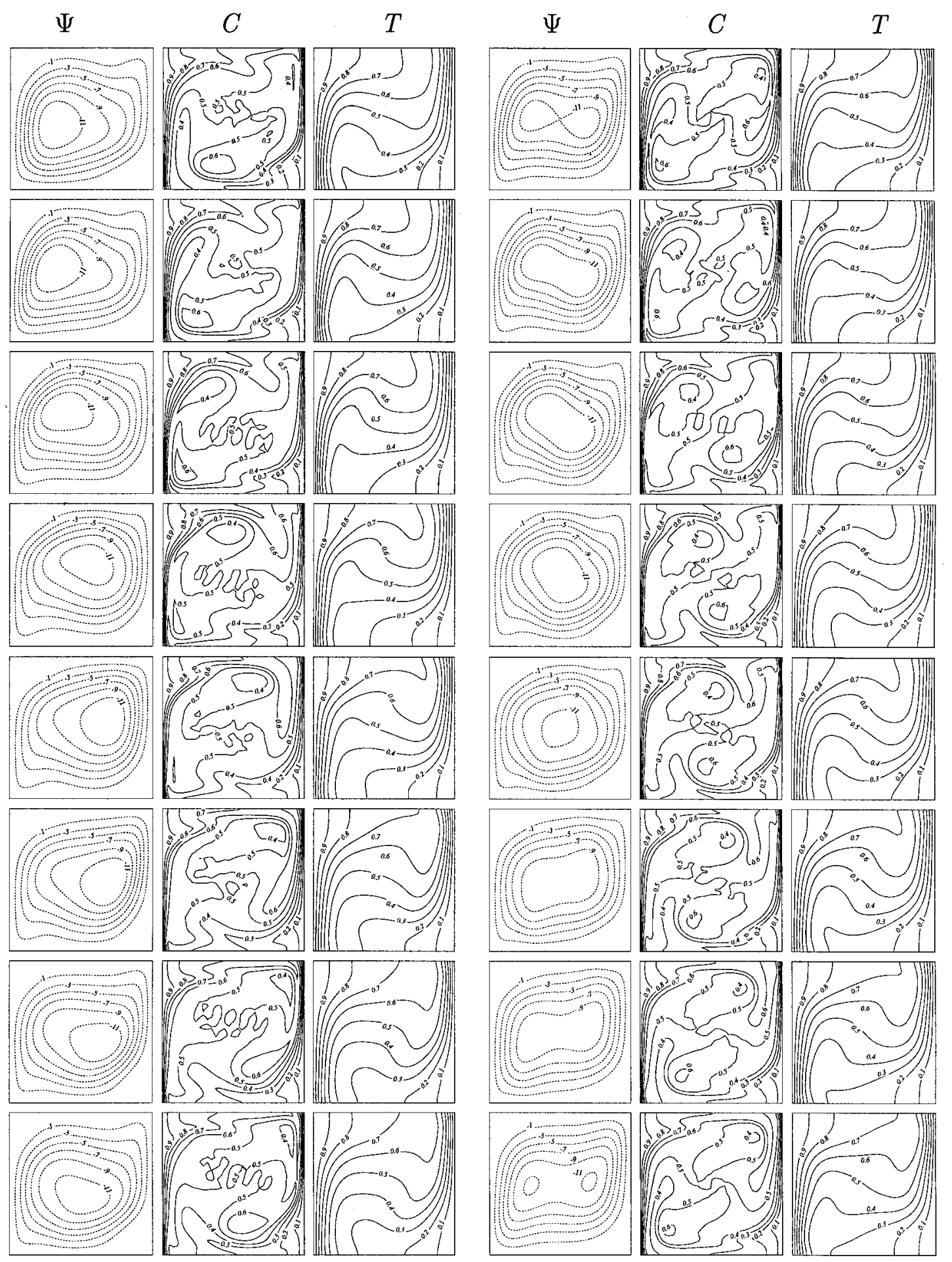

Fig. 11. Flow structure during eights moments of a period. Contours of the stream-function, concentration, and temperature fields are shown, the symmetry-breaking solution (left) and the centro-symmetric solution (right). $L e=21, G r_{\mathrm{T}}=9.0 \times 10^{4}$, Resolution is $31 \times 31$, time step is $5 \times 10^{-5}$. 

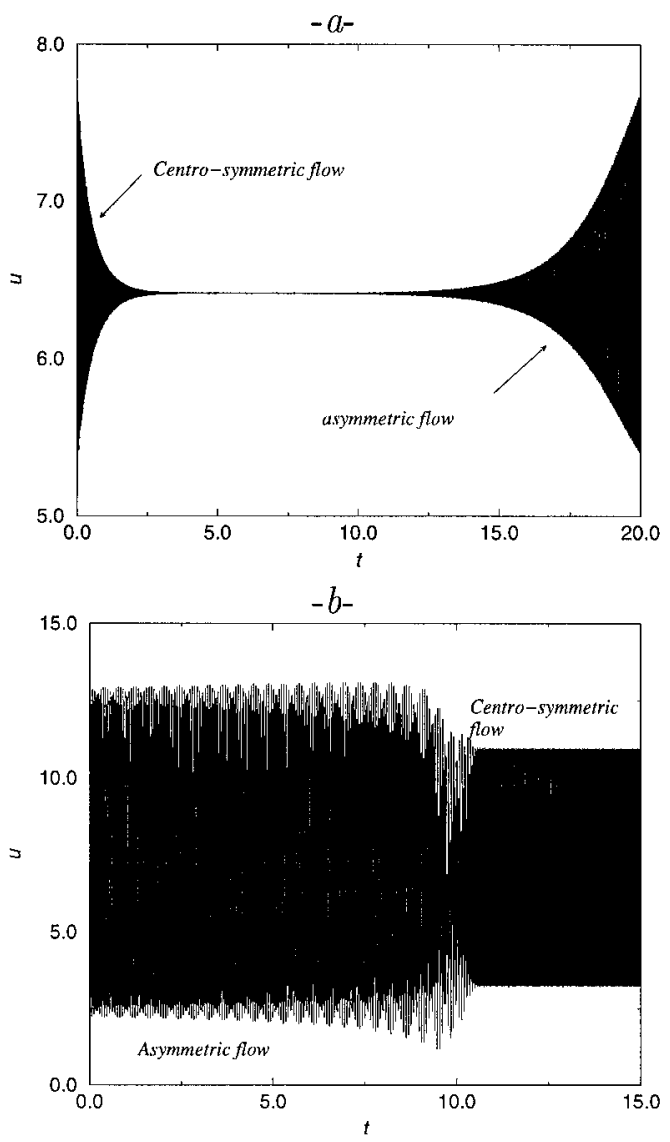

Fig. 12. $u(0.1329,0.5)$ as function of the time. Resolution is $31 \times 31$, time step is $10^{-4}$. (a): numerical simulation for $\left(L e=11, G r_{\mathrm{T}}=50000\right)\left(S_{\mathrm{b}}\right.$ zone $)$. The initial condition corresponds to a centro-symmetric flow for $\left(L e=11, G r_{\mathrm{T}}=55000>G r_{\mathrm{cl}}\right)$ ( $S_{\text {bc }}$ zone. (b): numerical simulation for $\left(L e=21, G r_{\mathrm{T}}=75000\right)\left(S_{\mathrm{c}}\right.$ zone). The initial condition corresponds to a centro-symmetric flow for $\left(L e=21, G r_{\mathrm{T}}=85000\right)\left(S_{\mathrm{bc}}\right.$ zone $)$. 

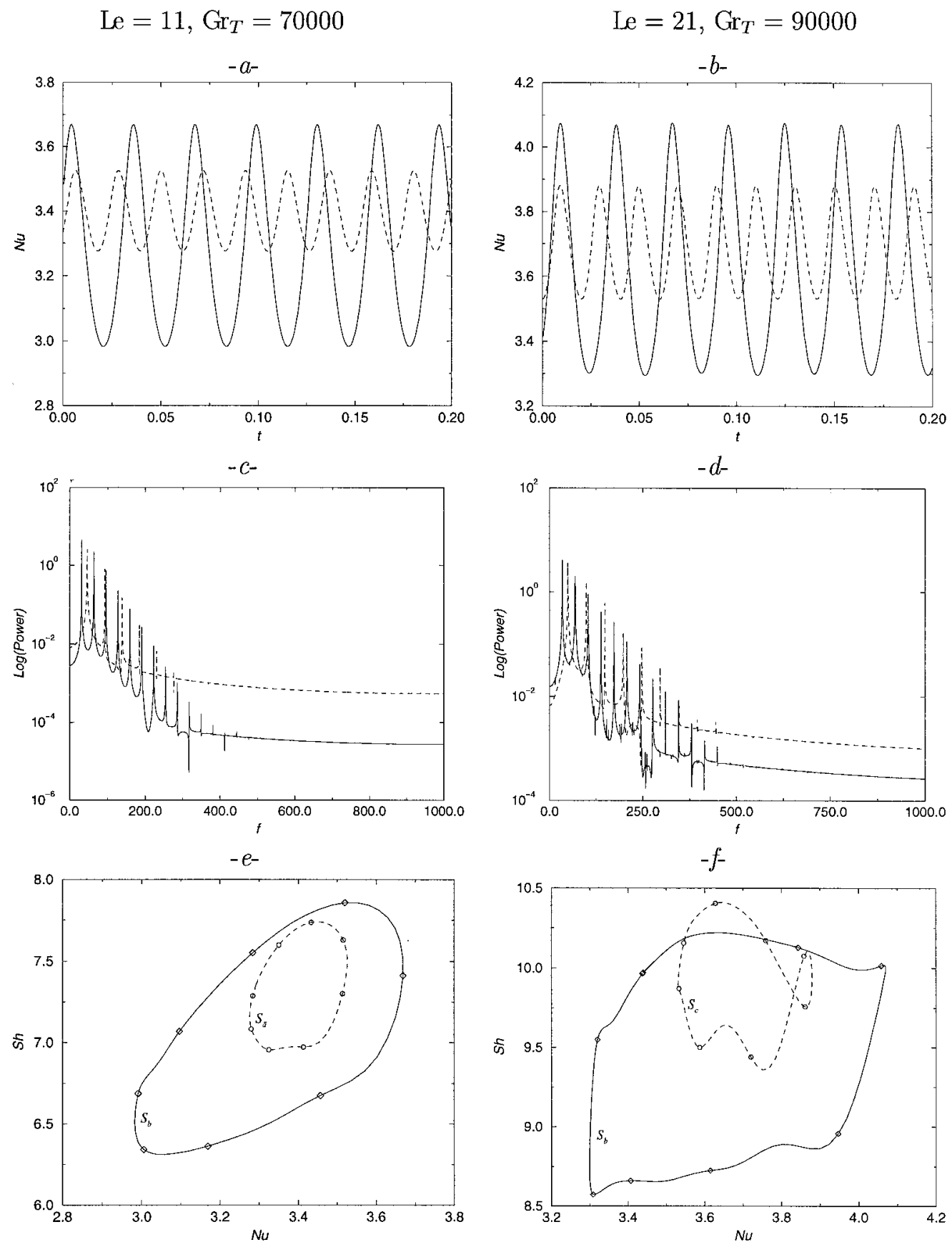

Fig. 13. Behavior of the Nusselt number as function of the time $t$ (a and b) and of the power of the specter of the oscillations as a function of the frequency (c and d). The dashed and solid lines designate the centro-symmetric flow and the centro-symmetry breaking flow, respectively. (e and f) designate $S h$ as function of $N u$ during a period. $\bigcirc$ and $\diamond$ correspond to the eight moments of a period plotted in Figs 10 and 11, respectively. Resolution is $31 \times 31$, time step is $10^{-4}$ and $10^{-5}$ for $L e=11$ and $L e=21$, respectively. 


\section{References}

[1] J.S. Turner, Double-diffusive phenomena, Annu. Rev. Fluid Mech. 6 (1974) 37-56.

[2] R.W. Schmidt, Double diffusion in oceanography, Annu. Rev. Fluid Mech. 26 (1994) 255-285.

[3] W.R. Wilcox, Transport phenomena in crystal growth from solution, Prog. Crystal Growth and Charact. 26 (1993) 153-194.

[4] J.S. Turner, Multicomponent convection, Annu. Rev. Fluid Mech. 17 (1985) 11-44.

[5] H.E. Huppert, J.S. Turner, Double-diffusive convection, J.Fluid Mech. 106 (1981) 299-329.

[6] Y. Kamotani, L.W. Wang, S. Ostrach, H.D. Jiang, Experimental study of natural convection in shallow enclosures with horizontal temperature and concentration gradients, Int. J. Heat Mass Transfer 28 (1985) 165-173.

[7] A. Bergeon, K. Ghorayeb, A. Mojtabi, Double diffusive instability in an inclined cavity, to appear in Phys. Fluids.

[8] H.D. Jiang, S. Ostrach, Y. Kamotani, Unsteady thermosolutal transport phenomena due to opposed buoyancy forces in shallow enclosures, J. Heat Transfer 113 (1991) 135-140.

[9] J.A. Weaver, R. Viskanta, Natural convection in binary gases due to horizontal thermal and solutal gradients, J. Heat Mass Transfer 113 (1991) 141-147.

[10] D. Gobin, R. Bennacer, Double diffusion in a vertical fluid layer: Onset of the convective regime, Phys. Fluids 6 (1) (1994) 59-67.

[11] S.A. Thorpe, P.P. Hutt, R. Soulsby, The effect of horizontal gradients on thermohaline convection, J. Fluid Mech. 38 (1969) 375-401

[12] S. Xin, P. Le Quéré, L.S. Tucherman, Bifurcation analysis of double-diffusive convection with opposing horizontal thermal and solutal gradients, Phys. Fluids 10 (4) (1998) $850-858$.

[13] K.Ghorayeb, A. Mojtabi, Double diffusive convection in a vertical rectangular cavity, Phys. Fluids 9 (8) (1997) 23392348

[14] T. Nishimura, M. Wakamutsu, A. Morega, Oscillatory double-diffusive convection in a rectangular enclosure with combined horizontal temperature and concentration gradients, Int. J. Heat Mass Transfer 41 (1998) 1601-1611.

[15] H. Zhou, A. Zebib, Oscillatory double diffusive convection in crystal growth, J. Crystal Growth 135 (1994) 587-593.

[16] J. P. Gollub, D.V. Benson, Many routes to turbulent convection, J.Fluid Mech. 100 (1980) 449-470.
[17] A. Batoul, H. Khallouf, G. Labrosse, Une méthode de résolution directe (pseudo-spectrale) du problème de Stokes 2D/3D instationnaire. Application à la cavité entraînée carrée, C.R.A.S. Paris 319 série II (1994) 1455-1461.

[18] J.W. Lee, J.M. Hyun, Double-diffusive convection in a rectangle with opposing horizontal temperature and concentration gradients, In. J. Heat Mass Transfer 33 (1990) 1619-1632.

[19] J.M. Hyun, J.W. Lee, Double-diffusive convection in rectangle with cooperating horizontal gradients of temperature and concentration, Int. J. Heat Mass Transfer 33 (1990) 1605-1618.

[20] G. Labrosse, E. Eric, H. Khallouf, M. Betrouni, A direct (pseudo-spectral) solver of the 2D/3D Stokes problem: transition to unsteadiness of nature convection flow in a differentially heated cubical cavity, Num. Heat Transfer part B 31 (3) (1997) 261-275.

[21] K. Ghorayeb, Etude des écoulements de convection thermosolutale en cavité rectangulaire, Ph.D. Thesis, Univérsité Paul Sabatier, Toulouse, France (1997).

[22] R. Bennacer, Convection naturelle thermosolutale: simulation numérique des transferts et des structures d'écoulement, Ph.D. Thesis, Univérsité Pierre et Marie Curie, Paris, France (1993).

[23] H. Khallouf, Simulation numérique de la convection thermo-vibrationnelle par une méthode spectrale, Ph.D. Thesis, Univérsité Paul Sabatier, Toulouse, France (1995).

[24] S. Xin, P. Le Quéré, L.S. Tucherman, Double diffusion in a square cavity: on the nature of the bifurcation at convection onset, Notes et Documents LIMSI (1996) 96-107.

[25] L.W. Wang, Y. Kamotani, S. Ostrach, Experimental study of natural convection in shallow horizontal cavity with different end temperatures and concentrations, Report FATS/TR-81-164, Case Western University, (1983).

[26] R. Krishnan, A numerical study of the instability of double diffusive convection in a square enclosure with a horizontal temperature and concentration gradients, ASME National Heat Transfer Conference, Philadelphia 1989 (ASME, New York, 1989), 357-368.

[27] T. Nishimura, T. Imoto, M. Wakamatsu, A numerical study of the structure of double-diffusive natural convection in a square cavity, Proc. of 4th ASME/JSME Thermal Eng. Conference 1 (1995) 193-200.

[28] T. Nishimura, T. Imoto, M. Wakamatsu, A numerical study of double-diffusive natural convection in a rectangular enclosure filled with binary gas, Trans. JSME Ser. B 62 (1996) 271-277. 